\title{
Displacement Fields Associated to Chemical Modulations in Sintered Ceramics After Spinodal Decomposition.
}

\author{
H.A. Calderon*, A. Huerta*, B. Martinez*, C. Kisielowski* \\ *Depto. Ciencia de Materiales, ESFM-IPN, UPALM Ed. 9, Apdo. Postal 75-707, México 07300. \\ *NCEM-LBNL, Berkeley CA 94720 USA.
}

Ceramics oxides in the system $\mathrm{FeO}-\mathrm{Fe}_{3} \mathrm{O}_{4}$ have been produced by means of mechanical milling and sintering for application as electromagnetic wave absorbers. Starting from powder mixtures of Fe and $\mathrm{Fe}_{3} \mathrm{O}_{4}$ or $\mathrm{Fe}$ and $\mathrm{Fe}_{2} \mathrm{O}_{3}$, as well as pure $\mathrm{Fe}_{3} \mathrm{O}_{4}$, a metastable solid solution of $\mathrm{Fe}$ and $\mathrm{O}$ has been produced. A low energy mill produces a solid solution after around $1000 \mathrm{~h}$ of milling. X-ray diffraction patterns show the formation of the solid solution but it is unclear whether a Fe lean wüstite or an oxygen rich magnetite is formed. However use of Mössbauer spectroscopy reveals an increasingly higher amount of metastable wustite $\left(\mathrm{Fe}_{(1-\mathrm{X})} \mathrm{O}\right)$ as a function of milling time i.e., $500 \mathrm{~h}$ and $1000 \mathrm{~h}$ of milling produce 67 and $74 \mathrm{~mol} \% \mathrm{Fe}_{(1-\mathrm{X})} \mathrm{O}$, respectively. Magnetic measurements also indicate the formation of a paramagnetic phase which corresponds most likely to wüstite. Consolidation of the mechanically milled powders has been achieved by means of plasma assisted sintering. Specimens sintered at relatively high temperature $(\mathrm{T}>1073 \mathrm{~K})$ show characteristics of a spinodal decomposition. Lower sintering temperatures $(673-773 \mathrm{~K})$ give rise to microstructures similar to the as-milled powders.

Conventional TEM and high resolution electron microscopy (HREM) have been used to characterize the spinodally decomposed microstructure found after sintering [1]. Nevertheless such characterization can be extended with the measurement of the displacement fields produced by the chemical modulation of cations in the material. Wüstite and Magnetite have a unique Oxygen lattice and a different distribution of Fe cations [2]. Magnetite and wüstite have both a cubic structure (spinel, $\mathrm{a}_{0}=0.8411 \mathrm{~nm}$ and $\mathrm{NaCl} \mathrm{a}_{0}=0.43538 \mathrm{~nm}$, respectively). Wüstite can have large deviations from stoichiometry. During the spinodal decomposition of the supersaturated wüstite formed during milling, a periodic array of domains of the two phases can be observed. Figure la shows a representative experimental HREM image showing the two phases $(B=[001])$. The different domains can be recognized more easily in Fig $1 \mathrm{~b}$ obtained by creating a Moire pattern. Fig. 2 shows the modulations in a different orientation $(\mathrm{B}=[111])$. Fig. 2a shows a experimental HREM image with some areas corresponding to the two phases. Careful observation shows a modulation in the intensity of the interference maxima corresponding to the cations i.e., the characteristic chemical modulation of an spinodal decomposition. Figure $2 \mathrm{~b}$ shows a reconstructed image from an area close to that in Fig. 2a. A through focal series has been used for the reconstruction process. The chemical modulation can also be observed in this case. However evaluation of the corresponding displacement fields has a higher accuracy than in the experimental images. Several strain maps have been produced in this manner.

References

1. A. Huerta, H.A: Calderon, M. Umemoto, M.E. Brito, Microcopy and Microanálisis 6 (Sup.2) (2000) 366.

2. M.E. Fine, Advances Mats. Research 4 (1970) 1.

Acknowledgements.

Support from CONACYT (Proy. 28952U) and NCEM-LBNL is gratefully acknowledged. The use of microscopes at NCEM-LBNL and the skillful assistance of Mr. C. Nelson are greatly appreciated. 

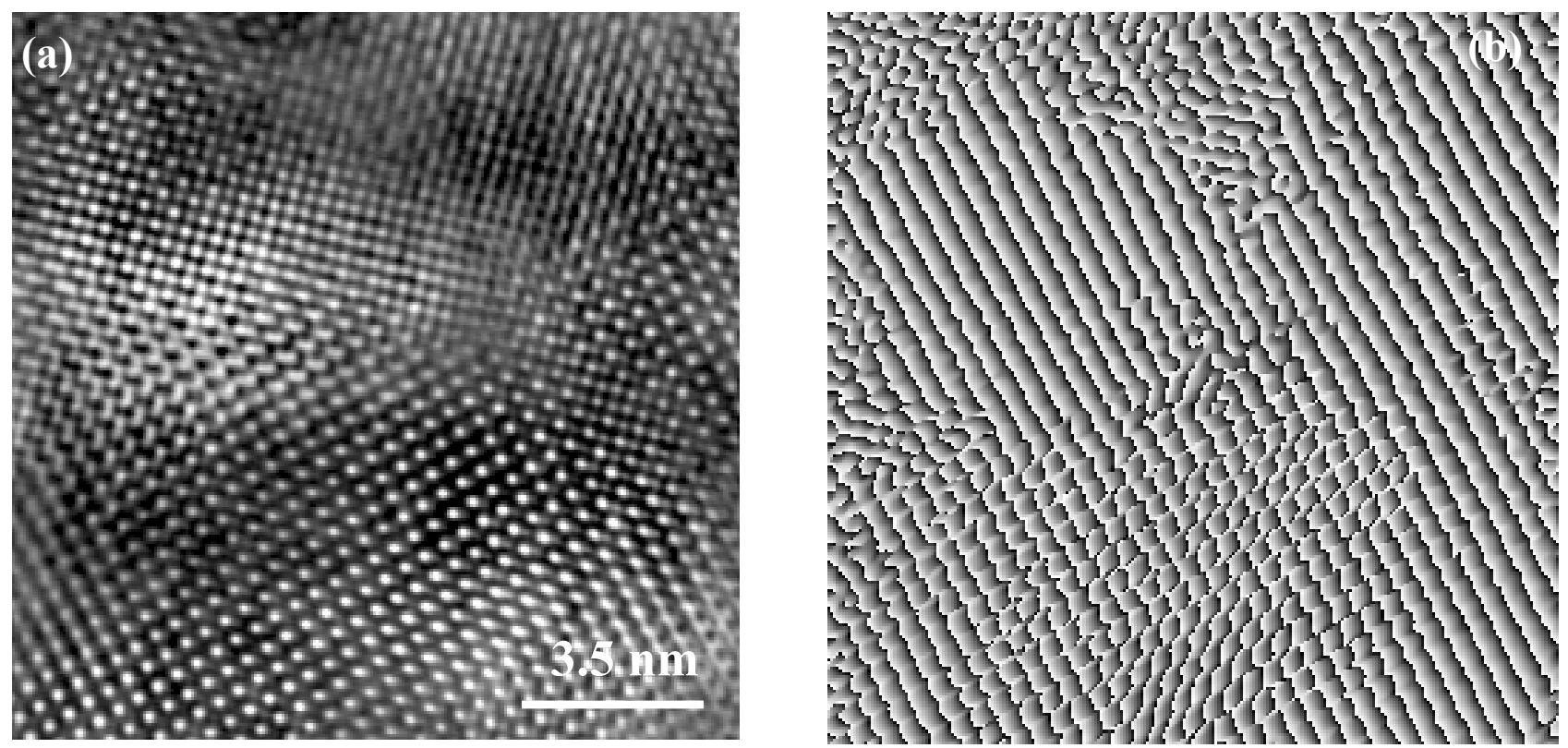

Figure 1. $\mathrm{Fe}_{3} \mathrm{O}_{4}-15$ at.\% Fe milled for $200 \mathrm{~h}$ and sintered at $1273 \mathrm{~K}$. (a) Experimental HREM image with $\mathrm{B}=[001]$. (b) Moire image formed with interference every two lines.
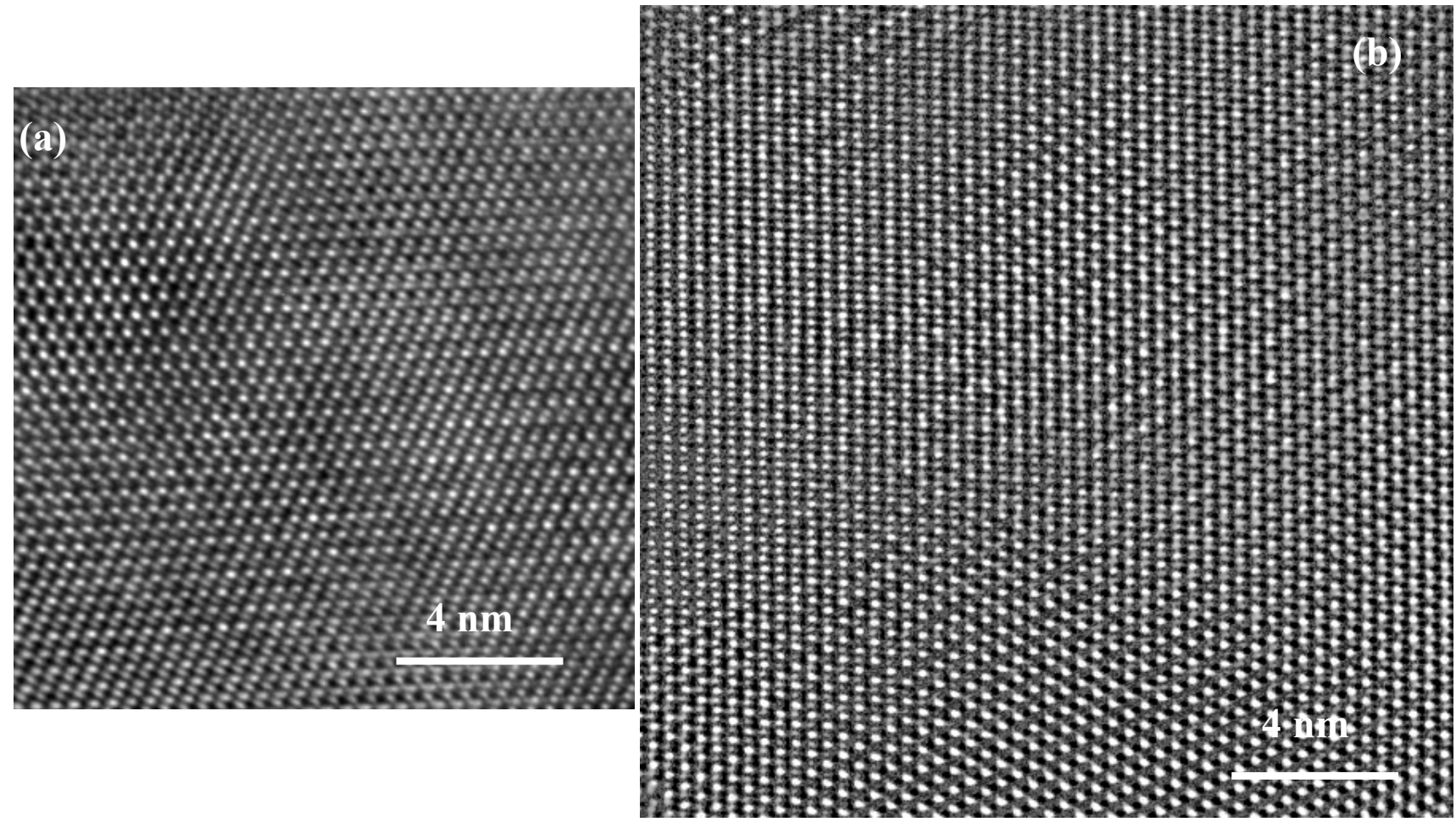

Fig. 2. (a) Experimental image corresponding to a $\Delta \mathrm{f}=-200 \mathrm{~nm}$. (b) Reconstructed image showing two phases and the corresponding chemical modulation. The nominal composition of the sample is $\mathrm{Fe}_{3} \mathrm{O}_{4}-15$ at.\% Fe milled for $600 \mathrm{~h}$ and sintered at $1273 \mathrm{~K}$. 